\title{
3D Numerical modelling of pile scour with free surface profile under waves and current using the level set method in model REEF3D
}

\author{
Nadeem Ahmad, Hans Bihs, Arun Kamath \& Øivind A. Arntsen \\ Department of Civil and Transport Engineering \\ Norwegian University of Science and Technology \\ Trondheim 7491, Norway
}

\begin{abstract}
Wave action stirs up sediments and keeps it in suspension while currents wash it away from the coastal zone. The combined action of the waves and current close to the sediment bed may worsen the situation by creating excessive sediment transport leading to the failure of hydraulic structures. In this study, numerical modeling of local scour under waves and current is carried out using the open source CFD model REEF3D, which solves the Navier-Stokes equation using the finite difference method. The simulated flow field from the Navier-Stokes equations is coupled with sediment transport algorithms in a numerical waves tank. Further, the calculated bedload and suspended load are linked with the Exner formula to calculate bed elevation changes. The free surface and scoured bed surface are captured using the level set method. Two case scenarios, namely scour under waves and scour under current are run until the equilibrium scour condition is achieved. The simulated results are compared with experimental data of Link (2006) and Sumer \& Fredsøe (2001). Good comparison between experimental data and simulated results is observed. It is observed that for equal flow velocity in the flume, sediment transport under current only condition is larger than under waves alone.
\end{abstract}

\section{INTRODUCTION}

Sediment transport under current has been studied extensively by many researchers using both physical as well as numerical models such as van Rijn 1984; Olsen \& Melaaen 1993; Kirkil et al. 2008; Bihs H. 2008; Bihs \& Ong 2009 and Bihs 2011. The sediment transport mechanisms are discussed in detail and it is concluded that sediment transport under current is caused by flow contraction and vortices around the structure (Melville 1992). Primarily, flow contraction induces large bed stresses which result in excessive sediment transport. Physical and numerical modelling of sediment transport under waves has been studied by many researchers such as Sumer \& Fredsøe 1992; Sumer \& Fredsøe 2001; Liu \& Garcia 2008; Ahmad et al. 2015; Ahmad et al. 2015a and Ahmad et al. 2015b. These studies concluded that sediment transport under waves depends on several factors such as flow contraction, streaming close to the boundary layer and vortices around the hydraulic structures (Sumer \& Fredsøe 1997). Specifically, when the waves flow interacts with hydraulic structures, flow contraction and vortices becomes primary driver for the local scour. Furthermore, the effect of vortices around the cylinder is very much dependent on the KeuleganCarpenter number. In this study, the Keaulegan Carpenter number (KC) is defined as ratio of the drag force over the inertia force in oscillating flow, which is defined as follows: $K C=U_{m} T / \mathrm{D}$, Where, $U_{m}$ is the maximum the undisturbed near-bed orbital velocity, $T$ is the waves period, $D$ is the cylinder diameter.

However, in a real case scenario, coastal regions are much influenced by the combined effect of waves and current, rather than just the action of waves or current alone (Sumer \& Fredsøe 2001). This effect is often seen during flood tides where currents and waves propagate in the same direction resulting in an increase of the wavelength. This change in waves length leads to an increase in wave velocity, Subsequently increase in the sediment transport along the direction of propagation. On the other hand, during the ebb tides, current is opposing the direction of waves propagation. This leads to shortening of the wavelength and higher waves heights, which result in breaking waves (Mei 1989). Eventually, in both situations, the change in hydrodynamics can cause excessive sediment transport which might lead to beach erosion, local scour, and revetment scour etc. 
The excessive sediment transport in the vicinity of hydraulic structures is an important concern for the stability of the hydraulic structures. It is primarily caused by horseshoe vortices at the upstream side, vortex shedding at the downstream side, and flow contraction at the side of the cylinder (Sumer \& Fredsøe 2001). Studies suggest that around the small diameter cylinders or small sized hydraulic structures, development of a weak vortex shedding regime takes place which cannot initiate sediment transport (e.g. Melville 1992; Ting \& Wei 2011; Roulund et al. 2005 and Ahmad et al. 2015c etc.). Therefore, most of the sediment transport under a current is mostly caused by flow contraction. The sediment transport under the waves is also caused by flow contraction because the presence of horseshoes vortices at the upstream side of cylinder and vortex shedding at the downstream side of the cylinder is assumed to be weak and insignificant for the small KC numbers $(K C<6.0)$ (Sumer \& Fredsøe 2001).

Local scour is also affected by diffraction effects, which depend on the diffraction parameter $D / L$, where $D$ is the diameter of cylinder and $L$ is the wavelength (Sumer \& Fredsøe 2001). According to Isaacson (1979), diffraction effects become significant, if $D / L$ is larger than 0.20 and an increment in $D / L$ results in an increase in the maximum scour depth. In the current study, $D / L=0.20$, which signifies that diffraction effect may contribute to sediment transport. Another non-dimensional parameter $U_{c w}$ is also discussed in the study. It is the ratio of the current velocity to the sum of maximum velocity of the waves and current velocity, which is defined as follows:

$U_{c w}=\frac{U_{c}}{U_{c}+U_{m}}$

Where, $U_{c}$ is the current velocity, $U_{m}$ is the maximum undisturbed orbital velocity close to the bed. In the present study $U_{c w}=1$, represents waves alone and $U_{c w}=0$ signifies current alone.

The present paper discusses numerical modeling of local scour under the waves and current. First, the local scour under the current is simulated. Results of the current scour are compared with experimental data of Link (2006) and then, the study is extended to simulate local scour under waves. The flow hydrodynamics is solved using the Navier-Stokes (RANS) equations, and the simulated flow field is coupled with sediment transport algorithms which calculate the bed stress considering the water viscosity and the eddy viscosity with the velocity gradient. Further, the calculated bed stresses are linked with bedload to calculate the change in bed elevation. The scour process is simulated until the equilibrium condition is achieved. The time development of scour and final scour contours are plotted. The results of waves scour are compared with experimental observations made by Sumer
$\&$ Fredsøe (2001). The maximum scour matched well with experimental data. Finally, It is concluded that the non-dimensional scour depth $(S / D)$ increase with the non-dimensional parameter $U_{c w}$.

\section{NUMERICAL MODEL}

The REEF3D model is used for the numerical modeling of the problem. It simulates the hydrodynamics using the Reynolds Averaged Navier-Stokes equations. The simulated flow fields are coupled with sediment transport algorithms to calculate the change in sediment bed levels with time. The different models used in the REEF3D are summarised as follows:

\subsection{Hydrodynamic model}

The numerical domain is uniformly discretised, and Reynolds Averaged Navier-Stokes (RANS) equations are used to calculate the flow field. The continuity equation and the momentum equations are defined as follows:

$$
\frac{\partial u_{i}}{\partial x_{i}}=0
$$

$$
\begin{aligned}
& \frac{\partial u_{i}}{\partial t}+u_{j} \frac{\partial u_{i}}{\partial x_{j}}=-\frac{1}{\rho} \frac{\partial P}{\partial x_{i}}+ \\
& \frac{\partial}{\partial x_{j}}\left[\left(\nu+\nu_{t}\right)\left(\frac{\partial u_{i}}{\partial x_{j}}+\frac{\partial u_{j}}{\partial x_{i}}\right)\right]+g_{i}
\end{aligned}
$$

where, $u_{i}$ is the mean velocity, $P$ is the pressure, $\rho$ is the density of water, $\nu$ is the water viscosity, $g$ is the gravitational acceleration.

The advection and diffusion terms of the RANS equations are discretised with the conservative WENO scheme (Jiang \& Shu 1996). The HamiltonJacobi version of the WENO scheme (Jiang \& Peng 2000) is used for the variables of the free surface and turbulence algorithms. Chorin's projection method (Chorin 1968) is used to model the pressure. A staggered grid is used to avoid odd-even decoupling between the pressure and the velocities. The third-order Total Variation Diminishing (TVD) Runge-Kutta scheme (Shu \& Gottlieb 1998) is used for time discretization. To optimize the time step size, an adaptive time stepping approach is used.

\section{$2.2 k-\omega$ Model}

$k-\omega$ model (Wilcox 1994) is used for the hydrodynamic turbulence calculation. It solves the partial differential equations for two variables namely, the specific turbulent dissipation $\omega$ which determines the scale of the turbulence and the turbulent kinetic energy $k$. The turbulent eddy viscosity $\nu_{t}$ is calculated 
using $k$ and $\omega$. The equations for the turbulent kinetic energy $k$ and the specific turbulent dissipation $\omega$ are defined as follows:

$$
\frac{\partial k}{\partial t}+u_{j} \frac{\partial k}{\partial x_{j}}=\frac{\partial}{\partial x_{j}}\left[\left(\nu+\frac{\nu_{t}}{\sigma_{k}}\right) \frac{\partial k}{\partial x_{j}}\right]+P_{k}-\beta_{k} k \omega
$$

$$
\frac{\partial \omega}{\partial t}+u_{j} \frac{\partial \omega}{\partial x_{j}}=\frac{\partial}{\partial x_{j}}\left[\left(\nu+\frac{\nu_{t}}{\sigma_{\omega}}\right) \frac{\partial \omega}{\partial x_{j}}\right]+\frac{\omega}{k} \alpha P_{k}-\beta \omega^{2}
$$

Where, $P_{k}$ is the turbulent production rate which is described as follows:

$$
P_{k}=\nu_{t} \frac{\partial u_{i}}{\partial x_{j}}\left[\frac{\partial u_{i}}{\partial x_{j}}+\frac{\partial u_{j}}{\partial x_{i}}\right]
$$

The remaining coefficients in equation (10) are taken as follows: $\alpha=\frac{5}{9}, \beta_{k}=\frac{9}{100}$ and $\beta=\frac{3}{40}$.

The limited value of the eddy viscosity $\nu_{t}$ in the formulation is accounted for. It avoids over production of the turbulence in over strained flow outside the boundary layer (Durbin 2009). Therefore, the minimum value of the eddy viscosity for the hydrodynamic model is calculated as follows:

$$
\nu_{t}=\min \left(\frac{k}{\omega}, \sqrt{\frac{2}{3}} \frac{k}{|\mathbf{S}|}\right)
$$

Also, while damping is inevitable under the waves and current action of the waves and current, it might cause over production of the $\mathbf{S}$ across the waterair interface causing unrealistic excessive turbulence across the interface, and further numerical error is the formulation. This problem is managed using formulation suggested by (Naot \& Rodi 1982). The free surface is captured using the level set method (Osher \& Sethian 1988). It uses a continuously signed distance function $\phi(x, t)$ to define the interface between two immiscible fluids, which is defined as follows:

$\phi(\vec{x}, t) \begin{cases}>0 & \text { if } \vec{x} \text { is in phase } 1 \\ =0 & \text { if } \vec{x} \text { is at the inter face } \\ <0 & \text { if } \vec{x} \text { is in phase } 2\end{cases}$

where $\phi(\mathrm{x}, \mathrm{t})$ is calculated using convection equations with externally generated velocity field $u_{j}$ from the RANS equations.

$$
\frac{\partial \phi}{\partial t}+u_{j} \frac{\partial \phi}{\partial x_{j}}=0
$$

\subsection{Boundary conditions}

The first simulation in this paper is carried out for the local scour under a current. An uniform flow is prescribed as inflow boundary condition. The pressure is assumed to be atmospheric pressure at the free surface. While, the inflow and outflow boundary conditions for the waves case are as follows: The waves at the inlet and outlet are managed using the Dirichlet boundary condition with the active wave generation and absorption based on shallow water theory. This method is a suitable choice for short domain simulations. It reduces the simulation cost by generating waves in a limited domain.

Boundary conditions for the top boundary wall is specified as a symmetry plane. It assigns the vertical velocities and horizontal velocity gradient to zero. The ghost cell immersed boundary method (Berthelsen \& Faltinsen 2008) is used to describe the solid boundaries in the flume. This method considers solid cells as fictitious cells and extrapolates the hydrodynamic solution into the solid region. Also, the side walls are considered as rough walls, and a noslip boundary condition is imposed, where velocities close to the wall are defined as follows:

$$
\begin{array}{r}
\frac{u}{u_{*}}=\frac{1}{\kappa} \ln \frac{z}{z_{0}} \\
u_{*}=\sqrt{\frac{\tau}{\rho}} \\
\tau=\rho u_{*}^{2}
\end{array}
$$

where $u$ is defined as depth average velocity, $u_{*}$ is the shear velocity, $\mathrm{z}$ is the height above the bed and $z_{0}$ is the characteristic roughness length that may present as $z_{0}=k_{s} / 30$.

Adaptive fine step sizing (Griebel, Dornseifer, \& Neunhoeffer 1998) is used which deals with the variable time step size requirement in transient flow problems. It calculates the time step size by accounting for the maximum cell velocity, grid size, viscosity and surface forces explicitly and ensuring convergence according to the CFL criterion. The side and top view of the used numerical setup with specified boundary conditions are shown in Figure 1 and Figure 2, respectively.

\section{SEDIMENT TRANSPORT MODEL}

\section{1 bedload calculations}

The sediment transport incipient motion is calculated using the Shields approach (Shields 1936), where the critical bed shear stress is calculated based on the specified critical Shields parameter. The critical bed shear stress is defined as the tractive force needed 
to initialise sediment movement. The effective bed stresses are calculated based on the turbulent viscosity formulation, defined as follows:

$\tau=-\rho\left(\nu_{t}+\nu\right) \frac{\partial u}{\partial z}$

where $u$ is depth-averaged flow velocity, $z$ is depth from the bottom, $\nu_{t}$ is the turbulent viscosity that is calculated from the turbulence model Zeng et al. (2005). Since the Shields diagram approach is a semiempirical approach, it does not account for in the bed slopes. In the present study, the change in critical bed stress due to the bed slope is also accounted for the modified critical bed stress which is calculated using Kovacs \& Parker (1994) method. The critical stress reduction factors $r$ accounts for both the longitudinal as well as the transverse slope, which is defined as follows:

$$
\begin{aligned}
& (1-\Delta) r^{2}+2\left(\frac{\Delta}{\sqrt{1+\tan ^{2} \theta+\tan ^{2} \alpha}}+\frac{\sin \theta}{\tan \varphi}\right) r \\
& +\frac{1+\Delta}{1+\tan ^{2} \theta+\tan ^{2} \alpha}\left(\frac{\tan ^{2} \theta+\tan ^{2} \alpha}{\tan ^{2} \varphi}-1\right)=0
\end{aligned}
$$

where $r$ is the reduction factor for the critical bed shear stresses, $\theta$ is the longitudinal bed slope, $\alpha$ is the transversal angle, $\varphi$ is the angle of repose, $\Delta$ is the effect of the lift force. Finally, the modified critical bed stress are calculated as follows:

$\tau_{c}=r \cdot \tau_{0}$

where $\tau_{0}$ is the critical bed shear stress calculated from the Shields diagram. The calculated effective stresses and critical bed stresses from the Shields diagram (Shields 1936) are coupled with the bedload calculation. The bedload is calculated using the van Rijn formulas (van Rijn 1984):

$\frac{q_{b, i}}{d_{i}^{1.5} \sqrt{\frac{\left(\rho_{s}-\rho_{w}\right) g}{\rho_{w}}}}=0.053 \frac{\left(\frac{\tau-\tau_{c, i}}{\tau_{c, i}}\right)^{2.1}}{\left(\left(\frac{\rho_{s} /\left(\rho_{w}-1\right) g}{\nu^{2}}\right)^{1 / 3}\right)^{0.3}}$

where, $\tau_{c, i}$ is the critical bed shear stress, $\rho_{s}$ is sediment density, $\nu$ is the kinematic viscosity of water, $\rho$ the density of the water, $g$ is the accelartion due to gravity, $d_{50}$ is the median sediment particle diameter.

\subsection{Morphological model}

Bed level changes are computed using the Exner formula, which is based on the conservation of the mass

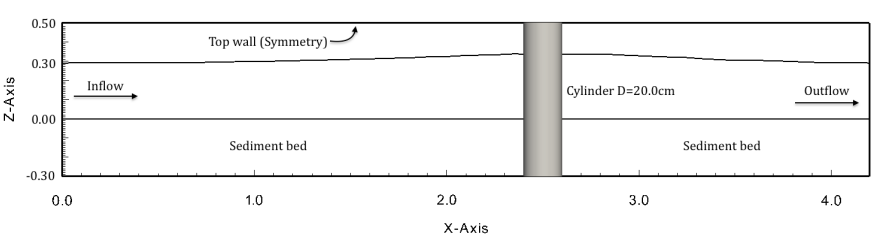

Figure 1: Numerical setup with specified boundary conditions (Side view)

of sediments transported by the flow, and deposited from suspension. It defines the temporal variation of scour considering the sediment porosity, the divergence of the bedload with erosion and deposition from suspended sediments. The Exner formula used for bed level change is described below:

$(1-n) \frac{\partial z_{b}}{\partial t}=-\frac{\partial q_{b, x}}{\partial x}-\frac{\partial q_{b, y}}{\partial z}-E+D$

where $q_{b}$ is the bedload, $\mathrm{n}$ is porosity, $z_{b}$ is local bed surface elevation, $E$ is the erosion rate and $D$ is the corresponding deposition rate from suspended sediments. Furthermore, The continuous erosion or deposition at one particular location leads to the formation of scour hole and sediment piling respectively. Naturally, the process keeps going until bed slope is less than the angle of repose. If the process further continues, an excess of sediment mass slumps into the neighbouring area. Considered that the process is relevant to scour where the excessive scour/deposition might take place, the sand slide algorithms are added to the morphological model to capture this effect numerically (Kovacs \& Parker (1994)) as discussed in Equation 12.

\section{SETUP}

\subsection{Experimental setup}

The experiments for sediment transport under the current are conducted at the hydraulic laboratory of the Technical University Darmstadt (Link 2006). A 37.0 $\mathrm{m}$ long, $2.0 \mathrm{~m}$ wide and $1.0 \mathrm{~m}$ deep re-circulating flume with a centrally placed cylinder $\mathrm{D}=0.20 \mathrm{~m}$, is used. The working section of the flume is made up of plexiglass to facilitate visual observations. The bottom of the flume trench is filled with fine sediments of $d_{50}=0.97 \mathrm{~mm}$ and density $\rho_{s}=2650 \mathrm{~kg} / \mathrm{m}^{3}$. The flow depth and sediment bed level are kept fixed to 0.30 $\mathrm{m}$ for all test runs. The inflow for the current is 0.18 $\mathrm{m}^{3} / \mathrm{s}$. The experiments are run until the equilibrium scour condition is achieved. The same experimental setup is also used for the scour under the waves. Finally, the time evolution of the scour, and maximum scour depth contours are plotted to gain an improved understanding of the local scour process. 


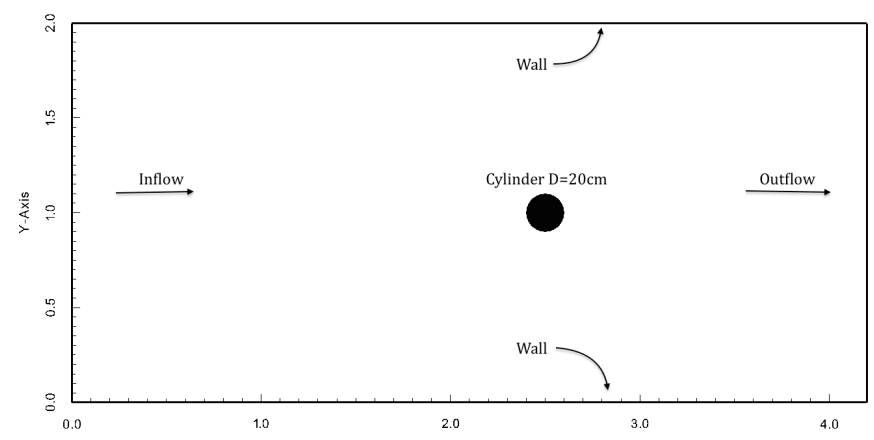

Figure 2: Numerical setup with specified boundary conditions (Top view)

\section{$4.2 \quad$ Numerical setup}

Instead of simulating the entire physical domain, only the scour affected domain is taken into the consideration. For the current case scenario, the simulated numerical domain is $10.0 \mathrm{~m}$ long, $2 \mathrm{~m}$ wide and almost $1 \mathrm{~m}$ high. A cylinder of $\mathrm{D}=20 \mathrm{~cm}$ is placed at the center location of the flume. The uniform cell size of $\mathrm{dx}=2 \mathrm{~cm}$ is used throughout the domain. The sediment bed level and flow depth and other sediment properties are the same as discussed in the experimental setup. The similar numerical setup is used for waves case scenario too. The still water depth is kept $0.30 \mathrm{~m}$ for the waves of period $\mathrm{T}=2.5 \mathrm{sec}$ and maximum waves velocity $U_{m}=15.7 \mathrm{~cm} / \mathrm{s}$. The experiments are run until the equilibrium conditions are achieved. The equilibrium scour around each pier is measured. However, the maximum non-dimensional scour $(S / D$, where $\mathrm{S}$ is the maximum scour depth and D is the diameter of the cylinder) are compared from the research made by Sumer \& Fredsøe (2001). The time evolution of the scour is also compared with experiment observations (Link 2006). The initial and final evolution of the scour matches well with the experimental data as shown in Figure 3. For the current scenario $\left(U_{c w}=1\right)$, an inflow and outflow depth $\mathrm{h}=0.30 \mathrm{~m}$ is maintained and an uniform flow velocity $\mathrm{U}=30 \mathrm{~cm} / \mathrm{s}$ is applied at the inlet. While, for the waves alone case scenario $\left(U_{c w}=0\right)$, the waves input is provided in the forms of waves amplitude and the wavelength, which are calculated from the wave period which is $T=2.5 \mathrm{~s}$ and $\mathrm{KC}=4.0$ (Sumer \& Fredsøe 2001). The fifth order cnoidal waves are generated using the active waves generation and absorption method.

It is important to note that as mentioned previously for the waves scenario too, instead of simulating the entire physical domain, only the scour affected domain $(4.2 \mathrm{~m}$ long, $2.0 \mathrm{~m}$ wide and almost $1.0 \mathrm{~m}$ deep) is simulated using the active waves generation and absorption method. This approach handles waves generation and absorption very accurately, even if the domain is smaller than the wavelength. In fact, the domain $4.2 \mathrm{~m}$ long (wavelength) is sufficient to generate a high-quality wave passing across around
Table 1: Test run using the REEF3D

\begin{tabular}{llll}
\hline & Scour under current & & Scour under wave \\
\cline { 2 - 2 } Parameter & $U_{c w}=1.0$ & & $U_{c w}=0$ \\
\hline Inflow $\left(\mathrm{m}^{3} / \mathrm{s}\right)$ & 0.18 & 0.0 \\
Still water depth (m) & 0.30 & 0.30 \\
KC number & 4.0 & 4.0 \\
Experimental (S/D) & 0.055 & 1.0 \\
Simulated (S/D) & 0.055 & 0.8 \\
\hline
\end{tabular}

the cylinder.

\section{RESULTS}

At first, the numerical simulation of local scour under current is carried out. Simulation is run until equilibrium scour is achieved. The time evolution of the local scour and maximum scour around the cylinder is analysed. Further, the time development of the scour and maximum scour value is compared with the experimental observation (Link 2006). A satisfactory match for the temporal scour and maximum scour depth is seen. Further, the validated setup is used to simulate scour under the wave. The numerical input is taken from the experiment run by (Sumer \& Fredsøe 2001) for the $\mathrm{KC}=4.0$. The simulation is run until equilibrium scour is achieved. The time development of the scour and maximum erosion from the vicinity of the pier is plotted in 3D contours. Finally, the results are compared with the Sumer \& Fredsøe (2001) study for the scour under the combined action of the waves and current as shown in Figure 6. The modeled scour under the waves is matched well with experimental observation. The simulated scour depth is 1.20 $\mathrm{cm}$ which is close to experimental scour depth, i.e., $1.20 \mathrm{~cm}$. Scour under the current, which is already matching well with the Link's experimental observation (Link 2006), is also compared with Sumer's nondimensional scour plot for waves and current (Sumer $\&$ Fredsøe 2001) as shown in Figure 10. The simulated scour depth is $14 \mathrm{~cm}$ while graph calculated value is around $18.0 \mathrm{~cm}$. The small difference between the simulated scour and plot should be justified because the experimental graph data is interpolated from the number of experiments run for different sediment particle size. The detailed discussion about the scour under the waves and current is covered in the next chapter. The basic detail of run scenarios, such as inflow, KC, final scour depth, is mentioned in Table 1 .

\subsection{Scour under current $\left(U_{c w}=1\right)$}

The simulation is run for the scouring under the current alone with $20 \mathrm{~cm}$ diameter in the center of the numerical flume. Constant inflow (velocity $0.30 \mathrm{~m} / \mathrm{s}$ ) conditions are maintained through out the simulation. The flow depth at the outlet is also kept fixed to observe a change in sediment bed topography while keeping the hydrodynamics conditions unchanged. 


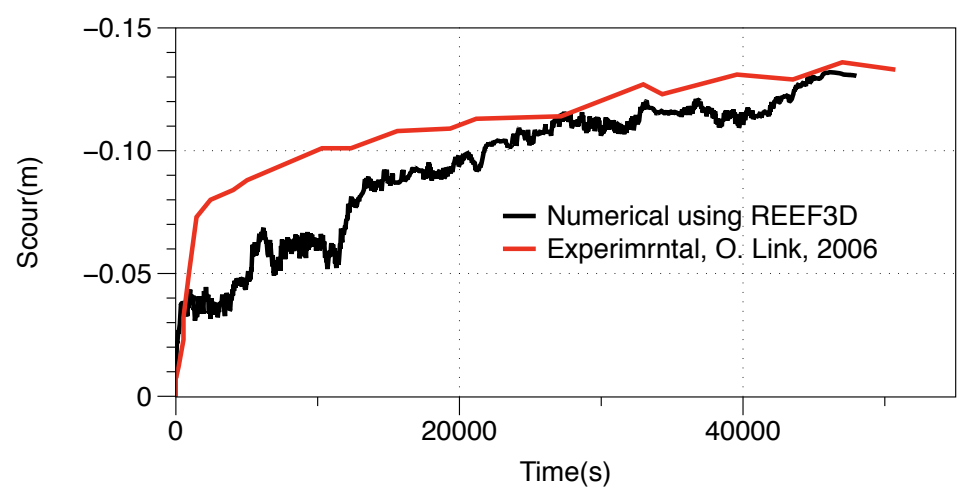

Figure 3: Temporal development of local scour under current, REEF3D simulated, experimental (Link 2006).

The simulation is run for 15 hours which is a sufficiently long time to analyse the equilibrium scour. The time evolution of the local scour and final topography is plotted to analyse the local scour process. The time evolution of the scour and final scour topography are shown in Figure 3 and Figure 4.

It is seen that the local scour rate is high at the beginning of the process. Almost 70 percent of the maximum scour takes place within the first $20000 \mathrm{sec}-$ onds, which is considered to be a very short time interval when the experiment is run for 15 hours to get equilibrium scour. For the remaining 30 percent scour, scour rate decreases rapidly and takes almost 10 hours to get equilibrium point. The small deviation in the scour development is also seen at an intermediate stage of the process, which signifies earlier convergence of the simulated equilibrium scour. In contrast, simulated equilibrium scour depth, which is important on the local scour, compares well with experimental data.

The 3D view of the final scour is shown in Figure 4. It is seen that maximum scour is taking place in the proximity of the cylinder. The simulated maximum scour depth is almost $14.0 \mathrm{~cm}$ which matches well with the experimental scour depth. The sediment deposition can also be seen at the upstream and downstream side of the cylinder.

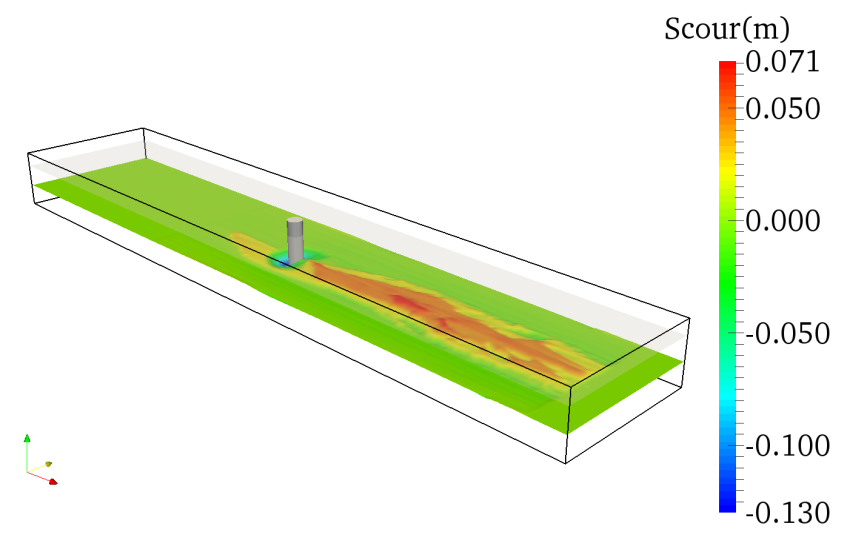

Figure 4: Simulated scour around the cylinder after 15 hours run
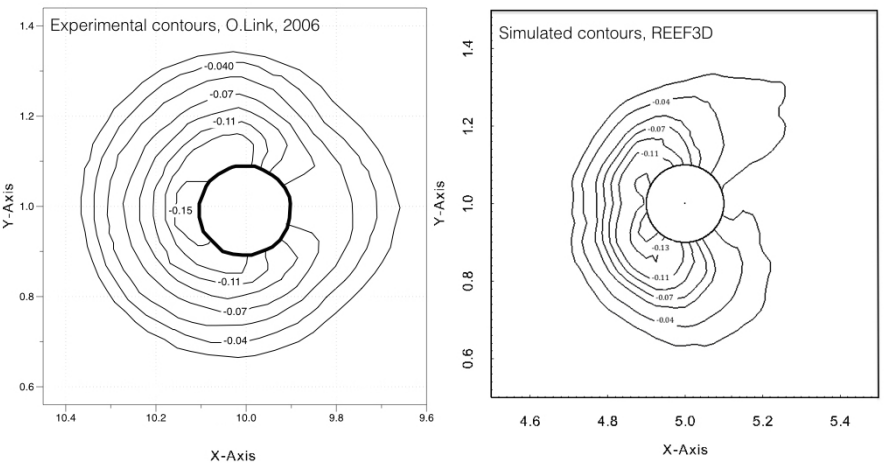

Figure 5: Comparison between physical (O. Link, 2006) and numerically simulated (REEF3D) contours

\subsection{Scour under waves $\left(U_{c w}=0\right)$}

In this section, local scour under the waves is discussed. The waves inputs are taken from Sumer's experimental research about local scour under the combined waves and current action (Sumer \& Fredsøe 2001). In the numerical simulation, first, a stable waves field is developed and then the simulated flow field is coupled with the sediment transport algorithm. It avoids unexpected scour before local sediment transport starts. The numerical simulation is run until equilibrium scour is achieved. It is found that the local increases exponentially and achieves equilibrium scour depth $1.20 \mathrm{~cm}$, which matches well with the observed scour depth of $1.20 \mathrm{~cm}$ (Sumer \& Fredsøe 2001).

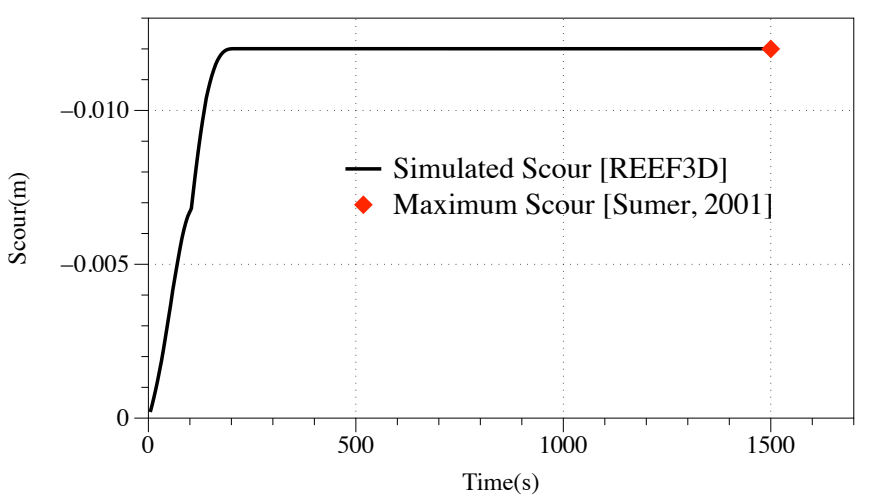

Figure 6: Time development of scour under the wave, $\mathrm{KC}=4.0$

It is seen that the temporal scour pattern is similar to the scour under the current condition. The maximum scour is taking place within the first $150 \mathrm{sec}-$ onds of the simulation and then it attains the equilibrium value if the simulation is run for sufficient time. The final scour pattern shows that only the upstream cylindrical edges are affected most by the local scour. The downstream side of the cylinder is affected by deposition. Ultimately, for small amplitude waves ( $K C=4.0$ ), little scour and deposition is taking place in the vicinity of the cylinder which would hardly affect the stability of the structure. The 3D scour domain, and the side view of the waves profile with scouring in the vicinity of the cylinder is shown in Figure 7 and Figure 8 respectively. 


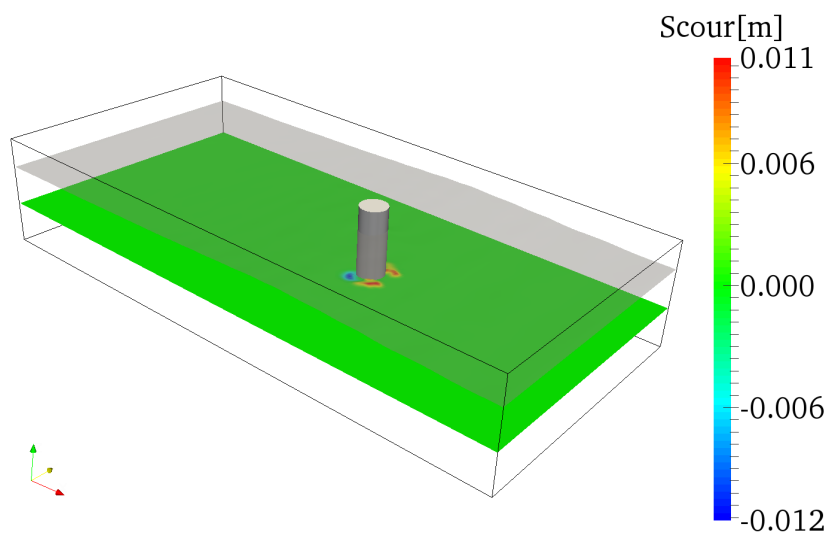

Figure 7: 3D simulated scour around the cylinder under the wave, $\mathrm{KC}=4.0$

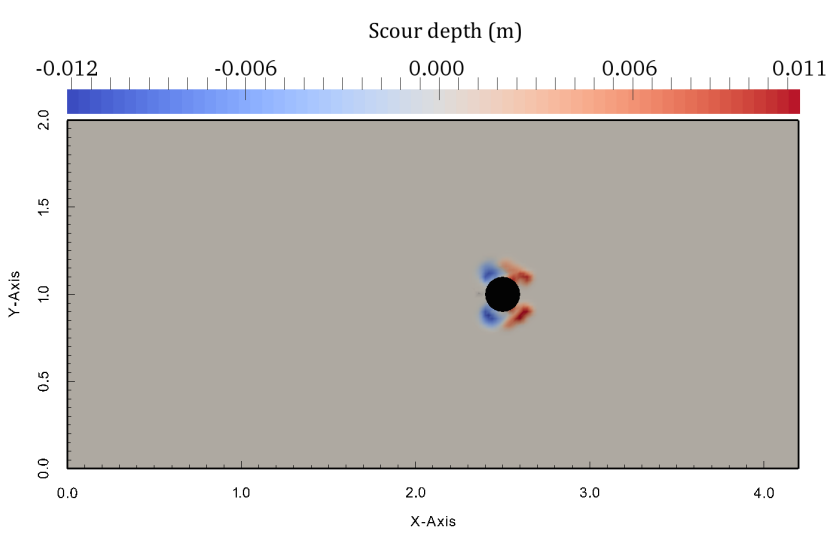

Figure 8: Scoured domain with free surface profile and waves velocity, top view

\section{CONCLUSION}

The local scour under waves, and a current action is satisfactorily analysed using REEF3D. The first case is run for local scour under the current. The temporal variation of the local scour and the equilibrium scour topography are compared with experimental data (Link 2006). A satisfactory agreement between the simulated and experimental results is seen. Then the same setup is used for the simulating local scour under the waves alone. Fifth-order cnoidal waves are generated using the active waves generation method. The waves flow resulting local scour is simulated until equilibrium scour depth is achieved. Furthermore, the maximum scour depth is compared with the experimental data (Sumer \& Fredsøe 2001) and a good match with the experimental results is seen. Ultimately, for both scenarios, the non-dimensional scour depth $(S / D)$ is compared with Sumer's (2001) analysis which shows the relationship between the non-dimensional scour depth $(S / D)$ and the nondimensional velocity parameter $U_{c w}$ as shown in Figure 10. Therefore, on the basis of whole analysis the following conclusions can be drawn:

\section{- Current alone develops highest scour.}

- Waves alone develops lowest scour.

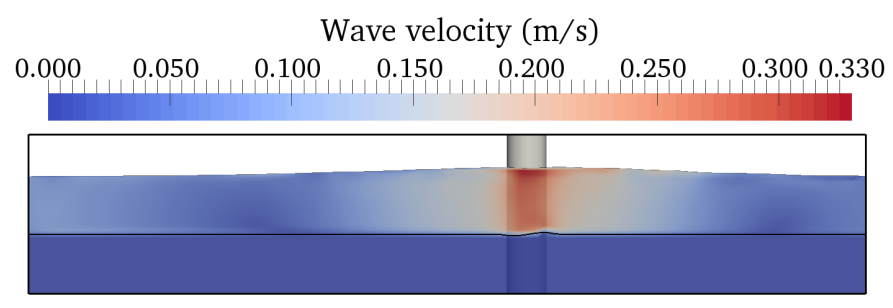

Figure 9: Scoured domain with free surface profile and waves velocity, side view along the flow direction [immediate vicinity of cylinder at $\mathrm{Y}=1.1 \mathrm{~m}]$

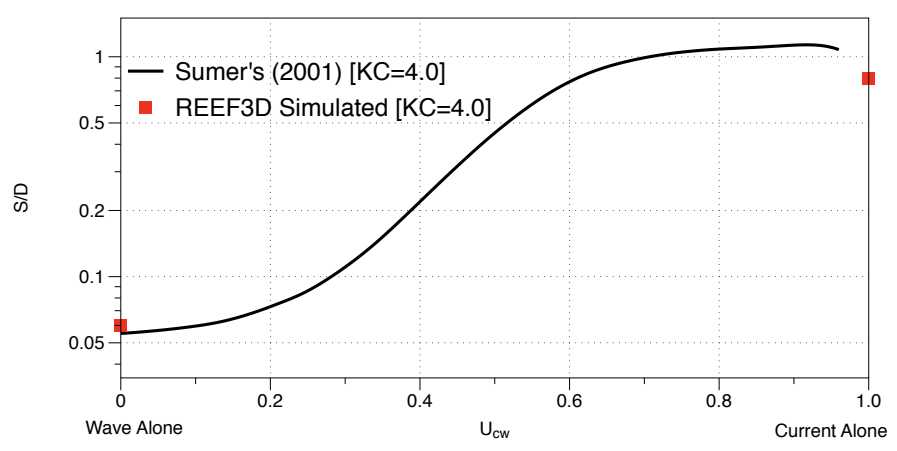

Figure 10: Non-dimensional maximum scour $(S / D)$ for $\mathrm{KC}$ $=4.0$, REEF3D simulated and Sumer's observation(Sumer \& Fredsøe 2001)

- For all flow scenarios, the simulated scour evolution with time follows the negative exponential function $\left(1-e^{x}\right)$ which signifies that scour develops very quickly in beginning and attains an equilibrium state after a long duration.

- The initial scour rate is high and almost $75 \%$ of the maximum scour takes place within the first 5 hours.

- The maximum scour under waves, and current signifies that non-dimensional scour $S / D$ increases with non-dimensional velocity parameter $U_{c w}$ as shown in Figure 10.

\section{OUTLOOK}

In this paper, two cases namely scour under the waves and scour under a current are discussed in detail. Furthermore, the combined action of waves and current, for different values of the non-dimensional velocity parameter $U_{c w}$, would an the extension of this study.

\section{ACKNOWLEDGEMENT}

This research work is supported by funding from the Polish-Norwegian Research Programme operated by the National Centre for Research and Development under the Norwegian Financial Mechanism 20092014 in the frame of Project Contract No. POLNOR/200336/95/2014 


\section{REFERENCES}

Ahmad, N., S. Afzal, H. Bihs, \& Ø. A. Arntsen (2015). Threedimensional numerical modeling of local scour around a non-slender cylinder under varying wave conditions. In 36th IAHR World Congress, June 2015, The Netherlands.

Ahmad, N., H. Bihs, A. Kamath, \& Ø. A. Arntsen (2015a). Cfd modeling of local scour around a pair of tandem cylinders under wave conditions. In Proceedings - International Conference on Port and Ocean Engineering under Arctic Conditions ( ISSN 0376-6756).

Ahmad, N., H. Bihs, A. Kamath, \& Ø. A. Arntsen (2015b). Numerical simulation of waves and local scour around vertical cylinders in a triangular arrangement using reef $3 \mathrm{~d}$. In MekIT15, Trondheim, Norway April 2015, Norway.

Ahmad, N., N. Bihs, A. Kamath, \& . A. Arntsen (2015c). Threedimensional cfd modeling of wave scour around side-by-side and triangular arrangement of piles with reef $3 \mathrm{~d}$. Procedia Engineering 116, 683-690.

Berthelsen, P. A. \& O. M. Faltinsen (2008). A local directional ghost cell approach for incompressible viscous flow problems with irregular boundaries. Journal of Computational Physics 227, 4354-4397.

Bihs, H. (2011). Three-dimensional numerical modeling of local scouring in open channel flow. Report, Department of Hydraulic and Environmental Engineering, Norwegian University of Science and Technology, Trondheim, Norway.

Bihs, H. \& M. C. Ong (2009). Numerical simulation of flows past partially-submerged horizontal circular cylinders in free surface waves. In Proc. 32nd International Conference on Ocean, Offshore and Arctic Engineering, Nantes, France.

Bihs H., O. N. (2008). Three dimensional numerical modeling of pier scour. In 4th International Conference on Local Scour and Erosion, ISCE 2008, Tokyo, Japan.

Chorin, A. (1968). Numerical solution of the navier-stokes equations. Mathematics of Computation 22, 745-762.

Durbin, P. A. (2009). Limiters and wall treatments in applied turbulence modeling. Fluid Dynamics Research 41, 1-18.

Griebel, M., T. Dornseifer, \& T. Neunhoeffer (1998). Numerical simulation in fluid dynamics: a practical introduction. SIAM.

Isaacson, M. (1979). Wave induced forces in the diffraction regime. Pitman Advanced Publishing Program.

Jiang, G. S. \& D. Peng (2000). Weighted eno schemes for hamilton-jacobi equations. SIAM Journal on Scientific Computing 21, 2126-2143.

Jiang, G. S. \& C. W. Shu (1996). Efficient implementation of weighted eno schemes. Journal of Computational Physics 126, 202-228.

Kirkil, G., S. G. Constantinescu, \& R. Ettema (2008). Coherent structures in the flow field around a circular cylinder with scour hole. Journal of Hydraulic Engineering 134(5), 572587.

Kovacs, A. \& G. Parker (1994). A new vectorial bedload formulation and its application to the time evolution of straight river channels. Journal of Fluid Mechanics 267, 153-183.

Link, O. (2006). Untersuchung der Kolkung an einem schlanken zylindrischen Pfeiler in sandigem Boden. Wasser Abwasser GWF 147(6), 421-422.

Liu, X. \& M. Garcia (2008). Three-dimensional numerical model with free water surface and mesh deformation for local sediment scour. Journal of Waterway, Port, Coastal and Ocean Engineering 134(4), 203-217.

Mei, C. C. (1989). The applied dynamics of ocean surface waves. World Scientific Publishing Co. Pte. Ltd.

Melville, B. W. (1992). Local scour at bridge abutments. Journal of Hydraulic Engineering 118(4), 615-631.

Naot, D. \& W. Rodi (1982). Calculation of secondary currents in channel flow. Journal of the Hydraulics Division, ASCE 108(8), 948-968.

Olsen, N. R. B. \& M. C. Melaaen (1993). Three-dimensional calculation of scour around cylinders. Journal of Hydraulic Engineering 119(9), 1048-1054.

Osher, S. \& J. A. Sethian (1988). Fronts propagating with curvature- dependent speed: algorithms based on hamiltonjacobi formulations. Journal of Computational Physics 79, $12-49$.

Roulund, A., B. M. Sumer, J. Fredsøe, \& J. Michelsen (2005). Numerical and experimental investigation of flow and scour around a circular pier. Journal of Fluid Mechanics 534, 351401.

Shields, A. (1936). Anwendungen der ähnlichkeitsmechanik und der turbulenzforschung auf die geschiebebewegung.

Shu, C. \& S. Gottlieb (1998). Total variation diminishing rungekutta schemes. Mathematics of Computation 67, 73-85.

Sumer, B. M. \& J. Fredsøe (1992). Wave scour around a large vertical circular cylinder. Journal of Waterway, Port, Coastal, and Ocean Engineering 127(3), 125-134.

Sumer, B. M. \& J. Fredsøe (1997). Wave scour around group of vertical piles. Journal of Waterway, Port, Coastal, and Ocean Engineering 124(5), 248-256.

Sumer, B. M. \& J. Fredsøe (2001). Scour around pile in combined waves and current. Journal of Hydraulic Engineering 127.

Ting, F.C. K., B. J. C. H. G. R. P. S. \& G. Wei (2011). Flume tests for scour in clay at circular piers. journal of hydraulic engineering. J. Hydraul. Eng., ASCE 127(11), 969-978.

van Rijn, L. C. (1984). Sediment transport, part i: Bed load transport. Journal of Hydraulic Engineering 110(10), 1431-1457.

Wilcox, D. C. (1994). Turbulence modeling for CFD. DCW Industries Inc., La Canada, California.

Zeng, J., G. Constantinescu, \& L. Weber (2005). A fully 3d nonhydrostatic model for prediction of flow, sediment transport and bed morphology in open channels. In $n$ Proceedings of the 31st IAHR Congress, pages 1327-1338. 